\title{
Jámblico en Estobeo: doctrinas sobre el alma transmitidas por la doxografía
}

Marta Alesso

Institutos de Estudios Americanos y Europeos (IDEAE), Universidad Nacional de La Pampa, Argentina alessomarta@gmail.com

\section{Resumen}

Juan Estobeo, en el límite del siglo quinto con el sexto, recopiló la más extensa colección de literatura filosófica de su tiempo, en especial del neoplatonismo que tiene profundas raíces en la época alejandrina y se asoma al Imperio bizantino con objetivos edificantes. Las doctrinas filosóficas que el Estobeo compila están atestadas de frases hechas, $\gamma \nu \tilde{\omega} \mu \alpha \mathrm{l}$, sentencias y recomendaciones morales, de allí su influencia sobre los florilegia bizantinos y medievales. El principal valor de la antología radica en la transmisión de textos no atestiguados por otra fuente. De hecho, el tratado titulado en latín De Anima de Jámblico solo sobrevive en las páginas de las Eclogae de Juan Estobeo, quien lo incluyó en su

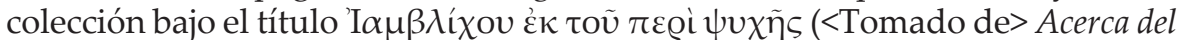
alma de Jámblico). El tratado Sobre el alma no figura en los listados canónicos de las obras de Jámblico, de hecho tampoco está en el TLG bajo la autoría del Calcidience. Me he basado, para observar los itinerarios de las teorías sobre el alma y su proyección en el mundo bizantino, en la edición alemana de Curtius Wachsmuth y Otto Hense (1884-1923) y para la traducción y comentario de los pasajes he consultado la versión inglesa de John Finamore y John Dillon (2003) y la italiana de Lucrezia Martone (2014).

Iamblichus in Stobaeus: doctrines on the soul transmitted by doxography

\begin{abstract}
Joannes Stobaeus, at the end of the fifth century, compiled the most extensive collection of philosophical literature by his times, especially referring to Neoplatonism, whith deep roots in the Alexandrian era and edifying purposes
\end{abstract}

Palabras clave

Estobeo Jámblico doxografía alma neoplatonismo
Keywords

Stobaeus lamblichus doxography soul Neoplatonism 
in the Byzantine age. The philosophical doctrines compiled by Stobaeus are full of ready-made phrases, $\gamma v \tilde{\omega} \mu \alpha \mathrm{L}$, judgments and moral recommendations, hence their influence on Byzantine and medieval florilegia. The main value of the anthology lies in the transmission of texts not recorded by another source. In fact, De Anima by Iamblichus only survives in the pages of the Eclogae by Joannes Stobaeus, who included it in his collection under the title ' $\mathrm{\alpha} \alpha \mu \beta \lambda$ í $\chi 0 v$

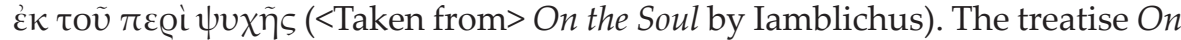
the soul does not appear in the canonical listings of the works by Iamblichus, in fact it is not in the TLG under the Chalcidencis' authorship. I have observed the itineraries of the theories about the soul and its projection on the Byzantine world, in the German edition of Curtius Wachsmuth and Otto Hense (1884-1923), for the translation and commentary of the passages I checked the English version by John Finamore and John Dillon (2003) and the Italian one by Lucrezia Martone (2014).

\section{Presentación}

El tratado titulado De Anima de Jámblico solo sobrevive en las páginas de las Eclogae de Juan Estobeo, quien le dio lugar en su muy extensa antología bajo

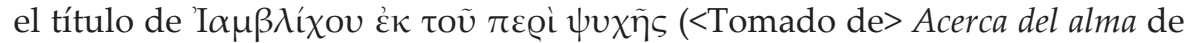
Jámblico). Se interesa el Estobeo en el texto de Jámblico desde un punto de vista doxográfico, de modo que gran parte de los fragmentos que nos transmite consisten en una crítica a opiniones filosóficas anteriores. La posición doctrinal de Jámblico -y por ende, la de Estobeo- se manifiesta entonces en un contexto de polémica y hasta enfrentamiento con sus predecesores, Plotino, Amelio y Porfirio. El tratado Sobre el alma no figura en los listados canónicos de las obras de Jámblico, de hecho tampoco está en el TLG bajo la autoría del Calcidience. Me he basado, para observar los itinerarios de las teorías sobre el alma y su proyección en el mundo bizantino, en la edición alemana de Curtius Wachsmuth y Otto Hense (1884-1923) y para la traducción y comentario de los pasajes he consultado la traducción inglesa de John Finamore y John Dillon (2003) y la italiana de Lucrezia Martone (2014). La importancia del tratado para la historia del platonismo fue señalada a mediados del siglo pasado por A. J. Festugière, quien tradujo al francés una versión anotada de los fragmentos de esta obra en el Apéndice del tercer volumen de La Révélation d'Hermès Trismégiste (1953:177-264). Festugière ubica estas reflexiones sobre problemas del alma, su naturaleza y su destino, en el contexto cultural -que implica una especie de koiné filosófica- en que se produjo un siglo antes el De anima de Tertuliano. Asimismo entendió que el Estobeo, preocupado por las exigencias de su propia composición, intervino el orden original del tratado de Jámblico, en correspondencia justamente con el de Tertuliano.

Juan Estobeo, en el límite del siglo quinto con el sexto, en una biblioteca al norte de Macedonia (actual Istip), recopiló la más extensa colección de literatura trágica y filosófica, aunque no faltan fragmentos de la épica y de la oratoria. Del género dramático prefirió a Eurípides -casi 850 citas-y a Menandro y, para las ideas filosóficas, el extenso neoplatonismo que hunde sus raíces en la época alejandrina y se asoma al Imperio bizantino con objetivos edificantes. Las doctrinas filosóficas que Estobeo compila están atestadas de frases hechas, $\gamma v \tilde{\omega} \mu \alpha \mathrm{L}$, sentencias y recomendaciones morales, de allí su influencia sobre los 
filósofos y científicos destacados en la Antigüedad. Esta ciclópea tarea de recopilación nos permite conocer con cierta fidelidad el itinerario y asunto de más de quinientos autores, muchos de ellos de manuscritos hoy perdidos.

Permítaseme en primer lugar una reflexión de tono general sobre el valor de la doxografía y una particular sobre el tratado De anima de Jámblico. El término 'doxografía', acuñado por Hermann Diels, quien a los 31 años de edad publicó su célebre Doxographi Graeci (1879), indica una forma de enunciación de las opiniones de autores precedentes, sin arriesgar juicio alguno sobre ellas. Se le ha criticado a Diels ${ }^{2}$ porque define la doxografía como un género literario consistente en la recopilación-objetiva y neutra- de puntos de vista de filósofos y científicos del pasado sobre filosofía, ciencia y otras materias. Me atrevo a afirmar que una compilación de esta naturaleza, más que una historia aséptica de las ideas previas a la época del doxógrafo, es la representación fidedigna de lo que en su propio tiempo es creencia y opinión más difundida, manifestada a través de una erudición (supuestamente desapasionada) que reconstruye el proceso que da origen a esas ideas. Esto es, el doxógrafo se sitúa en una verdad a priori y trata de darle coherencia y validez mediante el testimonio de autoridades pretéritas. Con esto quiero decir que el tratado sobre el alma que Estobeo adjudica a Jámblico dice más sobre el mismo Estobeo y las concepciones sobre el alma a fines del siglo quinto que sobre lo que pensaba Jámblico a fines del siglo tercero. Sería importante tener otra fuente para establecer una edición crítica del De anima, pero desafortunadamente no gozamos de las ventajas de una transmisión paralela. Esta circunstancia nos impide, para empezar, corroborar si la autoría de Jámblico es genuina y por tanto las opiniones compendiadas. Hay indudablemente errores o más bien atribuciones erróneas por parte de Jámblico -o de Estobeo- y es difícil discernir si las inexactitudes se deben a Jámblico o a Estobeo o a las antologías que puedan haber consultado. Hay además errores formales, comunes a casi todas las antologías, que genéricamente podríamos denominar 'errores de florilegio', cuya tipología es conocida y estudiada por la crítica textual. El más frecuente y característico consiste en que el antologista se esfuerza por dar a su pequeña ecloga la apariencia de un reducido todo. Por ello, no duda en introducir partículas o giros aseverativos o enfáticos (como oũv, $\mu \varepsilon \tau \dot{\alpha} \delta \dot{\eta} \tau \alpha \tilde{v} \tau \alpha$, $\tau$ oívvv) que remplazan la falta de contexto y subrayan el carácter apodíctico de los excerpta. El mismo fin persigue la supresión de las conjunciones y subordinantes, especialmente al comienzo de la ecloga. Más 'peligroso' es la introducción de imperativos y la sustitución de lo particular por lo general. Se busca que la ecloga parezca algo autónomo, desligada del contexto en que originariamente surgió.

La obra de Estobeo tampoco permaneció intacta, sin sufrir manipulaciones por los editores y copistas. En época posterior a Focio, es decir, al siglo noveno, la obra de Estobeo fue dividida en dos partes: las Eclogae Physicae et Ethicae, que comprendían los dos primeros libros de la obra original y el Florilegium, los dos últimos. ${ }^{3}$ Muchos de los parágrafos de De anima de Jámblico corresponden a las Eclogae.

Los fragmentos que nos transmite Estobeo dan la impresión de que la obra ya en su forma original era una extensa colección de citas para presentar distintas teorías sobre el alma. No obstante, Jámblico mismo expresa que no es una simple antología lo que pretende ofrecer, sino que su intención es la búsqueda de la verdad. Cuando habla de que el alma es una sustancia incorpórea ( $\dot{\alpha} \sigma \omega \mu \alpha \tau o \varsigma)$ refiere a la doctrina de varios filósofos y finalmente afirma:
2. Cfr. el subtítulo "Fundamental assumptions under attack" (38-39) del capítulo de Runia (1999) y el artículo de Zhmud (2001:esp. p.221) y la respuesta de Mansfeld (2010:161).

3. La labor de edición de Curtius Wachsmuth y Otto Hense (1884-1923) trató de enmendar la confusión y desorganización en la transmisión de los textos de Estobeo, pero cometió a su vez otras decisiones arbitrarias. Cfr. el apartado "The textual tradition" (pp.196-198) en el capítulo dedicado a Estobeo en Mansfeld; Runia (1997) y el artículo de Piccione (1999). Por su parte, el artículo de D'Ancona (2006) parte, el articulo de D'Ancona (2006) aporta comentarios interesantes sobre
las ediciones modernas existentes. 
4. Cfr. Aristóteles, Política $1274 \mathrm{~b}$ 37: Ética Nicomaquea 1105 11; Retórica 1354b 24.

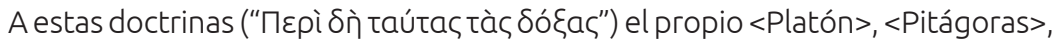
$<$ Aristóteles> y todos los antiguos, cuyos nombres han sido alabados por su sabiduría, adhieren por entero, si es que uno investiga sus opiniones con rigor científico. En cuanto a mí mismo, sobre ellas intentaré edificar todo el tratado ("праүнатвía"), preocupado por la verdad. (Estobeo 1.49.32.62-95).

Es con este término aristotélico, $\pi \varrho \alpha \gamma \mu \alpha \tau \varepsilon \varepsilon^{2} \alpha,{ }^{4}$ que Jámblico titula su trabajo, que sigue la misma metodología de Estobeo: recoger las opiniones de los filósofos que lo precedieron, antes de exponer la teoría propia. El texto del tratado de Jámblico ha sido mutilado y manipulado por Estobeo, la edición de Finamore y Dillon recupera en un "Appendix" (2003:229-278) los fragmentos del Calcidiense que no están presentes en Estobeo y pueden reconstruirse a partir de citas de Proclo, Simplicio y Prisciano, pero no voy a tenerlos en cuenta por el momento, sino que solo voy a hacer referencia a la fuente que aporta Estobeo para referirme a la idea que prima en el siglo sexto sobre la inmortalidad del alma, de indudable raigambre platónica, por lo cual es imprescindible hacer en primer lugar una referencia a qué es el alma para Platón.

\section{Qué es el alma}

Uno de los temas más debatidos de la filosofía antigua (y supongo que de la moderna) es el interrogante sobre qué es el alma y subsecuentemente su relación con el cuerpo y su trascendencia o continuidad vital después de la muerte de este. En realidad, utilizamos el término 'alma' para traducir $\psi v \chi \eta$, pero obviamente no abarcan ambos términos el mismo campo semántico. $\Psi v \chi \eta ́$ podría traducirse también como 'mente' puesto que está en relación directa con operaciones 'mentales' justamente, como pensar, racionalizar, juzgar y también por supuesto 'sentir' en un sentido lato que implica estados afectivos y emocionales.

Para Platón el alma es un principio de vida, según puede leerse en Fedón 105C 9-11. Recordemos que el Fedón es un diálogo que se presenta en un marco sumamente dramático. Sócrates pasa sus últimas horas antes de beber la cicuta conversando con sus amigos sobre la inmortalidad. Entiende que tan solo habrá una separación del cuerpo, que constituye una carga para el auténtico filósofo, quien en verdad percibe esa muerte como una liberación. "¿Qué es lo que ha de haber en un cuerpo que esté vivo?" pregunta Cebes. "El alma" ( $\psi v \chi \eta ́)$ responde Platón por boca de Sócrates.

En verdad, Sócrates no se pregunta en el Fedón qué es el alma, no es ese el problema a dilucidar. Más bien da por sentado que sus interlocutores aceptan que el alma se separa o se desprende del cuerpo en el momento de la

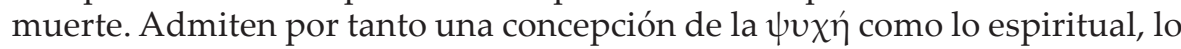
racional y lo vital, frente al cuerpo, $\sigma \tilde{\omega} \mu \alpha$, especie de receptáculo expuesto a la caducidad y a lo que percibe solo mediante los sentidos. Al cuerpo se le adjudican los apetitos y las pasiones, mientras que el alma es la parte noble del organismo.

En el Fedón, Platón defiende el dualismo cuerpo-alma y entiende que el alma es una realidad esencialmente inmortal. El alma anhela liberarse del cuerpo en un intento de retornar a su origen divino. La teoría platónica del alma, por influencia del orfismo, ${ }^{5}$ intenta explicar que el alma puede, ya que es una entidad distinta del cuerpo, entrar y salir de él. El cuerpo es concebido por 
tanto como una especie de cárcel o sepulcro. Platón, en el Crátilo (400c), adjudica a los seguidores de Orfeo la idea de que el cuerpo $(\sigma \tilde{\omega} \mu \alpha)$ es una tumba $(\sigma \tilde{\eta} \mu \alpha)$ donde el alma permanece confinada. Filón de Alejandría usa en diversos pasajes de su obra esta analogía. ${ }^{6}$ Por medio de la purificación y sobre todo por medio de la contemplación, el hombre puede liberar el alma y gozar su pura naturaleza no afectada por la percepción sensorial. Respecto del tema de la supervivencia del alma al cuerpo en el Fedón y su tratamiento por Filón de Alejandría han sido publicados últimamente una serie de trabajos interesantes, especialmente el libro de Sami Yli-Karjanmaa (2015) basado en la tesis doctoral, defendida en julio de 2013 en la Facultad de Teología de la Åbo Akademi University en Torku, Finlandia, titulado Reincarnation in Philo of Alexandria. En consonancia con esta tesis, pero oponiéndose en muchos lugares a ella, David Runia publicó en Circe 20 (2016), un artículo -que yo traduje del ingléstitulado "La recepción del Fedón de Platón en Filón de Alejandría", que trata los siguientes temas: a) la imagen del cuerpo como una prisión; b) la imagen del cuerpo como un ropaje del alma; c) la esclavitud que el alma debe sobre-

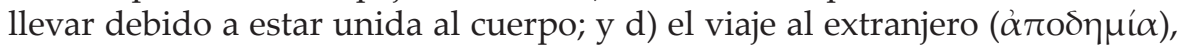
hacia otro lugar (Fedón 67c), que se corresponde con el tema bíblico de la migración. Es verdad que Filón no se refiere nunca explícitamente a la doctrina de la reencarnación ni expresa su aprobación o rechazo hacia ella. Sin embargo, es evidente que no desconocía el Fedón y la influencia de este diálogo en la filosofía helenística. Así se demuestra un derrotero, sin solución de continuidad, de las ideas expresadas por Platón respecto de la inmortalidad del alma, desde el siglo IV a.C., pasando por el llamado platonismo medio y el neoplatonismo hasta la época bizantina.

\section{La naturaleza del alma según Jámblico}

La edición alemana (Wachsmuth; Hense, 1884-1923) de Estobeo repone entre corchetes los nombres de los filósofos que ofician como sujeto en la citas de Jámblico. Por ejemplo, en Estobeo 1. 49.32.1-15, dice que "<Aristóteles $>$ (sic, el sujeto se repone entre corchetes) da a conocer los componentes del alma según

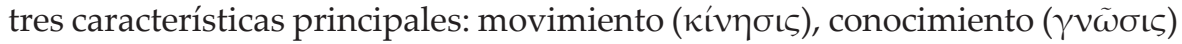

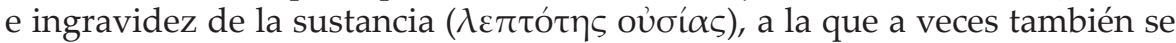

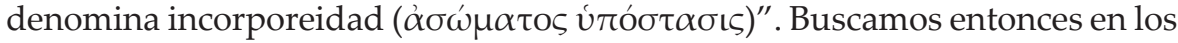
textos del Estagirita una afirmación semejante. Leemos en De anima 1.2.405b.11-

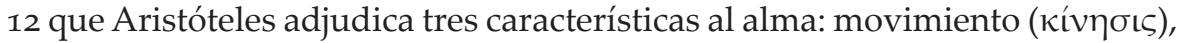

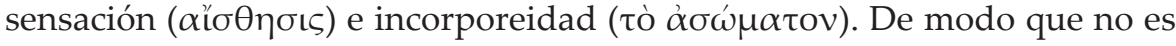
seguro que se refiera a Aristóteles, puesto que Jámblico señala cono la segunda característica la $\gamma \nu \tilde{\omega} \sigma \iota \varsigma^{7}$ y Aristóteles en verdad dice $\alpha$ ľo $\theta \eta \sigma \iota s$.

Otra afirmación de Jámblico, según la cita de Estobeo (1.49·32.16-23), es que el alma está compuesta de átomos:

<Algunos> retrotraen la sustancia del alma a los principios de los cuatro

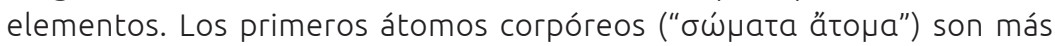

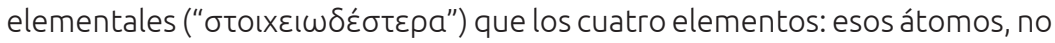
mezclados y completamente llenos de la primera y pura sustancia no portan ni un mínimo rastro de división. Estos cuerpos poseen un número infinito de formas -una de ellas es la esférica-, y de átomos se constituye el alma.

Esta posición 'atomista - no materialista' (llamémosle así) existe desde las primeras representaciones del alma (pensemos en Demócrito), y hay
6. Para un análisis de la metáfora del cuerpo ( $\sigma \hat{\omega} \mu \mathrm{a})$ como tumba (ఠn̂na) del alma en los textos de Filón de Alejandría, cfr. el artículo de Laura Pérez (2012).
7. El término үvŵбıç toma en la era cristiana la particular acepción de 'conocimiento integral' en asociación con ciertos esoterismos religiosos (cfr. Irineo, Contra los herejes 1.27.1; Hipólito, Refutación de todas las herejías 9.9.6; Ep. de Bernabé 1.12.3. 
expresiones seculares que la relacionan con alguno de los cuatro elementos: el alma se ha relacionado con el fuego, el fuego cósmico del cual hay una chispa en cada uno de nosotros; el alma luego de la muerte del cuerpo desciende al seno de la tierra; el alma es aire o aliento de vida o una realidad aérea que queda vagando alrededor de los vivos. Estas especulaciones fueron absorbidas por Platón, que tomó estas ideas y les dio la impronta que trascendió a través de los siglos. En sus primeras obras (en el Fedón, como dijimos), defendió el dualismo radical del cuerpo y el alma y que esta debe aspirar a liberarse del cuerpo para regresar a su origen divino y vivir, se puede decir, entre las ideas, en el mundo inteligible. Pero también es cierto que muy pronto Platón se dio cuenta de que este dualismo cuerpo-alma ofrecía no pocas dificultades, especialmente en el sentido de que cuerpo y alma no pueden ser entidades totalmente separadas; debía haber algún punto o lugar de inserción del alma en el cuerpo, para cumplir las actividades propias de la vida.

Los platonistas posteriores y especialmente los neoplatónicos también estuvieron preocupados por la resolución de este problema, que no es solo epistemológico sino también metafísico y moral. Jámblico (Estobeo 1.49.32.24-30) lo resuelve diciendo que el alma está indisolublemente asociada al cuerpo

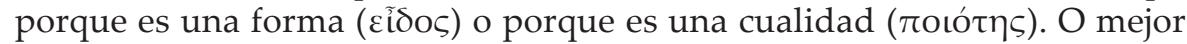
aún, el alma es 'la combinación de todas las cualidades' y es la cualidad principal entre ellas, ya sea porque es un resultado, sea porque existe antes que ellas.

Respecto de la escatología del alma, las ideas del calcidiense (Estobeo 1.49.65.27-

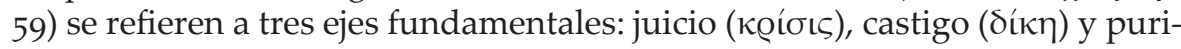

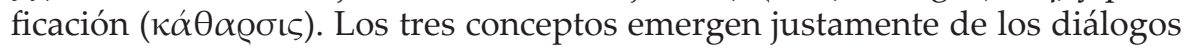
platónicos (Gorgias 523a-526d, Fedón 113d-114c, República 614b-621b -el mito de Er-, Fedro 248c-249d, Leyes 904c-905c). Según estos mitos, el alma, después de su vida sobre la tierra, deja el cuerpo cuando este muere y es llevada a otro lugar para ser juzgada. Si el alma ha llevado una vida sabia, es decir una buena vida desde el punto de vista filosófico, tendrá una recompensa, y si no, tendrá algún castigo específico y será purificada. Refiriéndose a la purificación

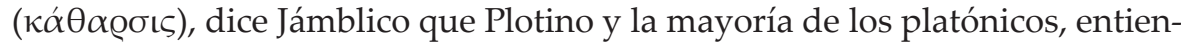
den que la purificación más perfecta consiste en un apartamiento ( $\alpha \pi$ ró$\theta \varepsilon \sigma \iota \varsigma)$ de las pasiones y de las imágenes y en tomar distancia de los pensamientos involucrados con la materia, en una plenitud ( $\pi \lambda \eta \dot{\varrho} \varrho \omega \sigma \iota \varsigma)$ del intelecto y del ser, y una asimilación ( $\dot{\alpha} \phi o \mu o i ́ \omega \sigma \iota \varsigma)$ del sujeto pensante con el objeto de su pensamiento.

Ahora bien, ¿cuál es el fin ( $\tau \varepsilon ́ \lambda o \varsigma)$, por el cual estos procesos de purificación,

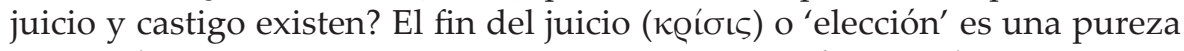

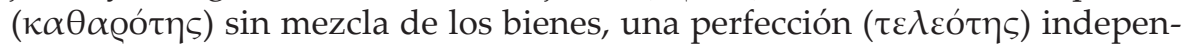
diente de las cosas bellas, apartada por completo de lo imperfecto, y una

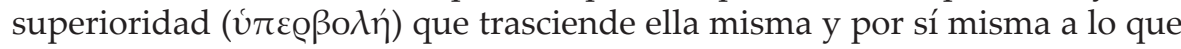
es superior, a lo que nada inferior puede unirse. Para otros el fin de la kó́oı es la disciplina ( $\varepsilon \dot{v} \tau \alpha \xi \hat{́} \alpha$ : la posibilidad de poner las cosas en un orden) para

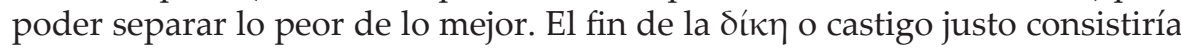
en que prevalecerá lo mejor sobre lo peor, en que se impedirá, se vencerá y se eliminará por completo el mal, y se construirá una igualdad imparcial

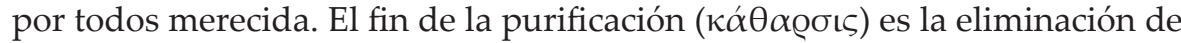
los elementos extraños, la restauración de la propia esencia, la perfección, la completud ( $\dot{\alpha} \pi 0 \pi \lambda \eta \dot{\rho} \omega \sigma \iota \varsigma)$, la autosuficiencia, el ascenso a la causa que nos ha engendrado. 


\section{Conclusión}

La posición genuinamente platónica está en la afirmación de Jámblico de que el alma es una sustancia incorpórea (Estobeo 1.49.32.62-95). Pero antes de esta declaración alude a la opinión de Numenio (fr. 48 p. 69 Theding), quien sos-

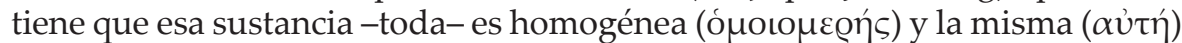
y una ( $\mu$ í $\alpha)$, de tal modo que en cualquiera de sus partes puede encontrarse la totalidad, que en todas las cosas existe el todo, aunque según una esencia propia en cada caso. Según esta doctrina (que Jámblico cita pero no toma como propia), el alma no difiere del intelecto ni de los dioses, ni de los seres superiores, al menos en lo que respecta a la sustancia como un todo. Jámblico dice que algunos (no es su propia opinión) afirman que en cada alma individual

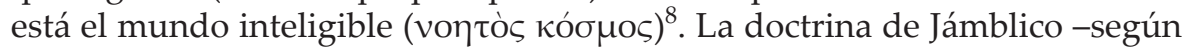
las citas de Estobeo- es contraria a esta: ubica al alma por separado, como que deviene en una instancia secundaria, después del intelecto (voũs), como una segunda hipóstasis; esa interpretación de que el alma sigue al intelecto la ubica en conexión con el intelecto ciertamente, pero también le concede una existencia independiente y propia. Entiende también que el alma está separada de todos los seres superiores y le asigna un límite a su propia esencia: el alma es un punto medio entre los seres divisibles e indivisibles o entre los corpóreos e incorpóreos. ${ }^{9}$ Agrega Jámblico que el alma puede ser "el pléroma de los principios del universo" con lo cual pone un término del gnosticismo en la definición: $\pi \lambda \eta ́ \varrho \omega \mu \alpha$. El Pléroma, según muchas doctrinas gnósticas de los siglos segundo y tercero, es el arquetipo que el Demiurgo copia (directa o indirectamente según la versión) para construir el mundo que conocemos. Esta copia del Pléroma -totalidad primigenia de la cual emanaban los eonesen todos los casos resulta deficiente e imperfecta. También define al alma como “lo que -después de las ideas- está al servicio de la obra de la creación, o la vida que tiene vida por sí misma porque procede del reino inteligible, o la procesión $(\pi \varrho o ́ o \delta o \varsigma)^{10}$ de las posibilidades del ser, verdadero y completo, hacia una sustancia inferior".

Jámblico -como aclaramos arriba- dice que adhieren a estas doctrinas Platón, Pitágoras, Aristóteles y todos los sabios de la Antigüedad, y él mismo preocupado por la verdad, va a basar su tratado en estas opiniones, pero de hecho en los intersticios de las citas aparece terminología propia de los siglos primeros de la era cristiana, aunque es una filosofía más bien en lucha con el cristianismo, si bien no deja de tener su influencia sobre la patrología y a través de ella en el pensamiento bizantino y medieval.

Para terminar, cuando hablo de 'alma' en este trabajo me refiero al alma individual, no al alma universal o Alma del Mundo, en términos de Platón o de Plotino. Este alma no está conformada por una adición de partes sino que es un todo integrado, de este modo, el camino epistémico que busca liberar al alma de las cadenas que la atan debe propiciar una integración correcta, que venga a reflejar el equilibrio originario del alma. Por lo tanto, se entiende que no todas las almas están destinadas a este esforzado camino -y es esta justamente la diferencia sustancial con el cristianismo- solo el alma del sabio, del filósofo que decide que la contemplación del universo, en su armonía y equilibrio, llevará al alma su orden primordial.

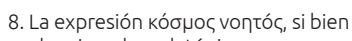
es de raigambre platónica, aparece por primera vez en Filón de Alejandría (véase por ejemplo La creación del mundo según Moisés, 19, 24, 25) y sirve para designar el mundo inteligible arquetipo de todas las cosas, del cual el mundo sensible es reflejo y copia. Plotino se la apropia y afirma en Enéada 3.4.3.21-23: "Es que el alma es muchas cosas; es todas las cosas, tanto las de arriba como las de abajo pasando por toda la gama de vida. Y así, cada uno de nosotros somos un universo inteli-

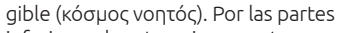
inferiores de este universo estamos en contacto con lo sensible, mientras que por las partes superiores de ese mismo universo estamos en contacto con lo inteligible" (traducción de Jesús Igal (1985) levemente retocada).

9. Jámblico indudablemente está haciendo una interpretación de Timeo 35a, donde Platón afirma que el demiurgo: "Entre la sustancia indivisible, eterna e inmutable y la divisible que sería la de los cuerpos estableció un punto medio y mezcló una tercera clase de sustancia, hecha de los otros dos". 10. En este término 'procesión' (así traduce Jesús Igal (1985) la palabra

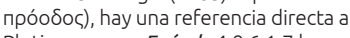
Plotino, que en Enéada 4.8.6.1-7 lo usa para la explicación de la bajada de las almas: "Así pues, no debe existir solo lo Uno (हैv), pues si no, habrían quedado latentes todas las cosas, que, estando en lo Uno, carecerían de forma; además, no existiría ninguno de los seres si lo Uno se hubiera quedado en sí mismo, ni existiría la multiplicidad de los seres sensibles, engendrados a partir de lo Uno (ánò toû ह̇vòc), si no se hubiese

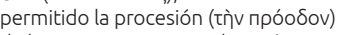
de los seres que vienen después, o sea, los que han obtenido rango de almas, y de la misma manera, tampoco deben existir solo las almas sin que hicieran su aparición los seres originados por ellas". 


\section{Q Bibliografía}

》 Burnet, J. (ed.) (1967-1968). Platonis Opera. 5 vols. Oxford: Clarendon Press (19001907).

" Courcelle, P. (1966). "Le corps-tombeau Platon, Gorgias 493a, Cratyle 400c, Phèdre 250c)", REA 68, 101-122.

" D’Ancona, C. (2006). "À propos du De Anima de Jamblique", Revue des sciences philosophiques et théologiques 90/ 4, 617-640.

»Finamore, J. F.; Dillon, J. M. (2003). Iamblichus. De Anima. Text, translation and commentary. Leiden - Boston - Koln: Brill.

» Henry, P., Schwyzer, H.-R.; Lewis, G. (1988 [1959]). Plotini Opera. Tomus II: Enneades

" IV-V. Oxford: Clarendon Press.

» Henry, P.; Schwyzer, H.-R. (2005 [1964]). Plotini Opera. Tomus I: Porphyrii Vita Plotini; Enneades I-III. Oxford: Clarendon Press.

» Igal, J. (Intr., trad. y notas) (1985). Plotino. Enéadas III-IV. Madrid: Gredos.

" Mansfeld, J. (2010). «Deconstructing doxography». En: Mansfeld, J.; Runia, D.T. Aëtiana. The Method and Intellectual Context of a Doxographer. Vol. 3: Studies in the Doxographical Traditions of Ancient Philosophy. Leiden/ Boston: Brill, 161-172.

" Mansfeld, J.; Runia, D.T. (1997). Aëtiana. The Method and Intellectual Context of a Doxographer. Leiden - New York - Koln: Brill.

» Martín, J. P. (ed.) (2009-2016). Filón de Alejandría. Obras Completas. Vols. I-V. Madrid: Trotta.

" Martone, L. I. (2014). Giamblico. De Anima. I frammenti, la dottrina. Prefazione di Henri Dominique Saffrey. Pisa: Univ. de Pisa.

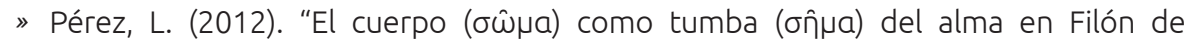
Alejandría: Uso y resignificación de una metáfora", Circe 16, 123-138.

»Piccione, R. M. (1999). "Caratterizzazione di lemmi nell' Anthologion di Giovanni Stobeo", RFIC127. 139-175.

" Runia, D. (1999). "What is doxography?". En: van der Eijk, P. (ed.). Ancient histories of medicine: Essays in medical doxography and historiography in Classical Antiquity. Leiden: Brill, 33-55.

"Runia, D. (2016). "La recepción del Fedón de Platón en Filón de Alejandría", Circe 20, 91-112.

» Wachsmuth, C.; Hense, O. (1884-1923). Johannes Stobaeus. Anthologium. 5 vol. Berolini: Wiedmann.

"Zhmud, L. (2001). "Revising doxography: Hermann Diels and his critics", Philologus 145.2, 219-243. 